\title{
Emoji y expresión escrita: posibilidades de aplicación y desarrollo en lenguas materna y extranjera
}

\author{
Milagrosa Parrado-Collantesic \\ Universidad de Cádiz, Puerto Real, Cádiz, España \\ José Luis Estrada-Chichón ${ }^{\mathrm{i} i(i)}$ \\ Universidad de Cádiz, Puerto Real, Cádiz, España
}

\begin{abstract}
Resumen
Este trabajo explora las posibilidades de aplicación de emoji como elementos visuales con naturaleza conceptual al desarrollo de la escritura en ámbitos académicos para lenguas materna y extranjera. Los resultados se centran en el análisis de 620 emoji insertados en comentarios realizados por estudiantes $(\mathrm{N}=18)$ del Grado en Educación Primaria (2019-2020) de la Universidad de Cádiz, España, en español e inglés, respectivamente, sobre ocho fotos subidas a la red social Instagram. Estos emoji se clasifican en ocho categorías según la Emojipedia, mostrando un comportamiento similar en las dos lenguas a partir de tres focos de análisis principales: distribution, uses y utterances (DANESI, 2016). El estudio termina justificando el valor manifiestamente conceptual de los emoji, pudiéndose atisbar sus aplicaciones didácticas a la enseñanza de lenguas materna y extranjera, así como al desarrollo de las habilidades de escritura en Educación Primaria, por ejemplo, como elementos que potencian el significado del texto.
\end{abstract}

Palabras clave

Emoji. Lengua escrita. Enseñanza de la lengua materna. Enseñanza de idiomas.

\section{Emoji e expressão escrita: possibilidades de aplicação e desenvolvimento} em línguas maternas e estrangeiras

\begin{abstract}
Resumo
Este trabalho explora as possibilidades de aplicar emoji como elementos visuais com natureza conceitual ao desenvolvimento da escrita em ambientes acadêmicos para línguas maternas e estrangeiras. Os resultados estão focados na análise de 620 emojis embutidos nos comentários feitos por estudantes $(\mathrm{N}=18)$ da licenciatura em Educação Primária (2019-2020) da Universidade de Cádiz, Espanha, em espanhol e inglês, respectivamente, em oito fotos enviadas à rede social Instagram. Estes emojis são classificados em oito categorias de acordo com a Emojipedia, mostrando comportamento semelhante em ambas as línguas a partir de três focos principais de análise: distribution, uses e utterances (DANESI, 2016). O estudo termina justificando o valor manifestamente conceitual dos emojis, podendo vislumbrar suas aplicações didáticas ao ensino da língua materna e de línguas estrangeiras e ao desenvolvimento da escrita no Ensino Fundamental, por exemplo, como elementos que valorizam o significado do texto.
\end{abstract}

\section{Palavras-chave}

Emoji. Língua escrita. Ensino da língua materna. Ensino da língua estrangeira.

Educ. Form., Fortaleza, v. 6, n. 1, e3528, jan./abr. 2021

DOI: https://doi.org/10.25053/redufor.v6i1.3528

https://revistas.uece.br/index.php/redufor/index ISSN: 2448-3583 


\title{
Emoji and written language: application and development possibilities in
} mother tongue and foreign language

\begin{abstract}
This work explores the possibilities of applying emoji as visual elements of a conceptual nature to the development of writing in academic contexts for both first and foreign languages. The results are focused on the analysis of 620 emoji embedded in comments made by students $(\mathrm{N}=18)$ of the Degree in Primary Education (2019-20) of the University of Cádiz, Spain, in Spanish and English, respectively, on eight pictures uploaded to the Instagram social network. These emoji are classified in eight categories according to Emojipedia, exhibiting similar behaviour in both languages concerning three main focuses of analysis: distribution, uses and utterances (DANESI, 2016). The study ends by justifying the manifestly conceptual value of emoji, with a look at their didactic applications to the teaching of first and foreign languages and to the development of writing skills in Primary Education, for example, as elements which enhance the meaning of the text.
\end{abstract}

\section{Keywords}

Emoji. Written language. Mother tongue instruction. Foreign language instruction.

\section{Introducción}

Una de las características señaladas por Prensky (2010) acerca de los nativos digitales, en contraposición con los inmigrantes digitales, es la preferencia de los nativos por los gráficos en pos de los textos. En este amplio sentido de "los gráficos", encontramos los emoji. La generación en la que se desarrolla el presente estudio está indiscutiblemente compuesta por estos nativos digitales criados entre ordenadores; esta Generación $Z$ que está marcada "[...] por momentos y acontecimientos que los convierten en grupo, caracterizados por sus hábitos y consumos" (ÁLVAREZ; HEREDIA; ROMERO, 2019, p. 9). Así, podemos afirmar que el gran hábito indiscutible que distingue a este grupo generacional es el empleo de los emoji.

Los primeros emoji "[...] se desarrollaron a finales de los años 90 en Japón por la compañía de telecomunicaciones NTT DeCoMo como parte del primer sistema de internet para teléfonos móviles" (EVANS, 2017, p. 19). A partir de entonces, estos se han expandido por el mundo de una forma imparable e implacable, constituyendo un elemento de comunicación indispensable. Así, "[...] we are beginning to sense [...] that the traditional forms of language and writing are no longer able to carry out thought in the 
ways of the past"1 (DANESI, 2016, p. 88). Desde este punto de vista, Evans (2017) llega a cuestionarse si nos encontramos ante un nuevo lenguaje universal, lo que supone una ardua controversia entre los investigadores, quienes debaten el carácter retórico visual en relación con su semántica (JIBRIL; ABDULLAH, 2013); mientras que otros niegan su naturaleza como lenguaje independiente y universal por su significado en un contexto (ZHOU; HENTSCHEL; KUMAR, 2017). Con todo, y teniendo en cuenta las perspectivas planteadas, para casi todos los casos, los emoji acompañan al texto, atendiendo a su naturaleza híbrida (DANESI, 2016).

Al hilo de estas ideas, se considera necesario hacer hincapié en el concepto de multimodalidad, donde incluimos a los emoji como un elemento más de esta, a tenor de la definición de López Pena (2020, p. 6):

[...] una disciplina que se preocupa del significado que se crea a través de las diferentes configuraciones y combinaciones que pueden tener en un mismo mensaje la imagen, el gesto, la mirada, la postura corporal, el sonido, la escritura, la tipografía, la música o el discurso, entre otros elementos.

En estas combinaciones, "[...] people interact by editing, sharing, reading, and reacting to a great variety of graphic texts, videos, photos, and songs that reflect our

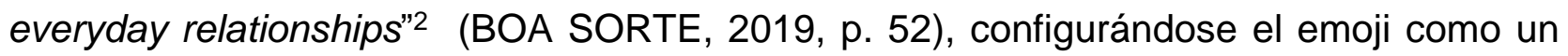
elemento vital en las relaciones y reacciones multimodales.

Se concluye con que el debate sobre el uso de tecnologías dentro del aula puede resolverse en que "[...] la misma tecnología digital que produjo los cambios en nuestros estudiantes también proporciona las herramientas para implementar por fin las formas de aprender más efectivas y reales" (PRENSKY, 2011, p. 9). Se considera este debate como superado, aunque no lo está el uso de otras estrategias poco usuales en la lengua y los textos académicos, como, en este caso, el desarrollo de la destreza escrita en el profesorado en formación inicial incluyendo el uso de emoji, tanto en L1 como en L2. Al respecto, hay algunos precedentes del uso de emoji con un fin didáctico, como, por ejemplo, determinados retos que invitan a adivinar la obra literaria a partir de una serie de emoji; o la propuesta de algunos docentes a que su alumnado los evalúen

1 "[...] estamos empezando a sentir [...] que las formas tradicionales de lenguaje y escritura ya no son capaces de llevar a cabo el pensamiento a la manera del pasado" (DANESI, 2016, p. 88, se tradució).

2 "[...] Las personas interactúan editando, compartiendo, leyendo y reaccionando a una gran variedad de textos gráficos, videos, fotos y canciones que reflejan nuestras relaciones cotidianas" (BOA SORTE, 2019, p. 52, se tradució).

Educ. Form., Fortaleza, v. 6, n. 1, e3528, jan./abr. 2021

DOI: https://doi.org/10.25053/redufor.v6i1.3528

https://revistas.uece.br/index.php/redufor/index ISSN: 2448-3583 
usando una gradación con emoticonos. No obstante, no dejan de ser prácticas aisladas que obvian que el emoji "[...] is further expanding the human potential to communicate"3 (EVANS, 2017, p. 14). Tanto es así que ningún género discursivo puede eludir su uso, incluyéndose, sobre todo y obviamente, en comentarios en redes sociales.

Tomando como referencia lo presentado hasta aquí desde un punto de vista teórico, en este trabajo se establecen dos objetivos de investigación principales:

- O.1. Determinar si los emoji pueden utilizarse como recurso para el desarrollo de la competencia escrita en contextos académicos formales.

- O.2. Examinar el uso de emoji en textos no académicos como, por ejemplo, publicaciones en Instagram, tanto en español como lengua materna (L1) e inglés como lengua extranjera (LE).

Del O.2. derivan dos objetivos específicos, según las implicaciones de los emoji como elementos activos en textos no académicos: 0.2.1. Analizar la aplicación sintáctica de los emoji en textos no académicos como sustitutos o adjuntos de texto en L1 y LE; y O.2.2. Considerar el uso del emoji en textos no académicos como "potenciador" del significado emocional del texto.

Esta investigación sirve para contextualizar una posible contribución dentro del marco de la formación inicial de maestros de Educación Primaria, así como la aplicación de emoji a la enseñanza de la competencia escrita tanto en L1 como en LE. Esto sirve para establecer dos hipótesis de investigación:

- H.1. El uso de emoji puede contribuir al desarrollo de la competencia escrita a partir de la transición de textos no académicos a textos académicos en L1 y LE.

- H.2. No existen diferencias significativas en el uso de emoji con independencia de si los textos se escriben en L1 o en LE.

Al igual que para los objetivos, de esta última hipótesis se desprenden dos más: H.2.1. Los emoji se utilizan principalmente como sustitutos de texto en escritos no académicos en L1 y LE.; y H.2.2. El uso de emoji es conceptual, tanto en cuanto acompañan al texto con la finalidad de potenciar su significado.

3 "[...] está ampliando aún más el potencial humano para comunicarse" (EVANS, 2017, p. 14, se tradució).

Educ. Form., Fortaleza, v. 6, n. 1, e3528, jan./abr. 2021

DOI: https://doi.org/10.25053/redufor.v6i1.3528

https://revistas.uece.br/index.php/redufor/index ISSN: 2448-3583 


\section{Metodología}

El presente estudio basado en la evidencia tiene un doble alcance: correlacional y explicativo. Lo correlacional supone determinar el grado de relación entre las variables número e intención de uso del emoji y lenguas. Lo explicativo sirve para aclarar las causas de la relación entre las variables, así como arrojar luz sobre las circunstancias que median entre ellas.

La investigación es de corte mixto cuantitativo (HERNÁNDEZ SAMPIERI; FERNÁNDEZ COLLADO; BAPTISTA LUCIO, 2016), ya que se desarrolla a partir de la recopilación de datos cuantitativos relacionados con los emoji $(\mathrm{N}=620)$ insertados en comentarios individuales de los participantes en ocho imágenes subidas a la aplicación y red social Instagram entre el 19 de febrero y el 22 de abril de 2020, realizados en L1 y LE. Además, se procedió a la recopilación de datos cualitativos a través de un foro virtual, una vez analizada la información cuantitativa. Las opiniones de los informantes giran en torno al uso verificado de los emoji, lo que representa una parte importante de sus interacciones digitales habituales (DANESI, 2016). En resumen, el procedimiento metodológico parte de (I) la compilación de los emoji; (II) el análisis de estos emoji; y (III) la verificación de los resultados junto a los propios participantes en la investigación.

Los informantes $(\mathrm{N}=18)$ casi conforman la población censal de estudiantes $(94,74 \%)$ que acudieron $(80,00 \%$ de asistencia) a la asignatura optativa Competencia Comunicativa en Lengua Extranjera II (Inglés) durante el curso académico 2019-2020. Esta asignatura queda encuadrada en el último semestre del Grado en Educación Primaria, dentro de la mención en lengua extranjera/AICLE de la Universidad de Cádiz (UCA), España. El 88,89\% son mujeres ( $N=16)$, mientras que el $11,11 \%$ son hombres $(\mathrm{N}=2)$. En materia idiomática, todos los alumnos son hablantes nativos de español, con la excepción de una estudiante con una competencia bilingüe (español-inglés) nativa total. Además, el 55,56 \% ( $\mathrm{N}=10)$ posee un nivel B1 según el Marco Común Europeo de Referencia para las Lenguas (CONSEJO DE EUROPA, 2002), mientras que el 27,78 \% $(\mathrm{N}=5)$ tienen un nivel B2. El resto $(\mathrm{N}=2)$ se asocia con los niveles $\mathrm{C} 1$ y $\mathrm{C2}$, respectivamente, mientras que una alumna todavía no posee ninguna acreditación oficial. Cabe destacar que todos los estudiantes de la UCA están obligados a obtener un nivel mínimo acreditado B1 en una lengua extranjera para obtener sus títulos de Grado. 
Los instrumentos que se han utilizado para la recogida de información se definen a continuación. En primer lugar, para los comentarios, los autores abrieron un perfil en la red social Instagram, debido a que la propia compañía estima que "[...] around 40 percent of the posts contain at least one emoji"4 (DANESI, 2016, p. 45). Este perfil llevaba el nombre de la asignatura y se les pidió a los estudiantes que se abrieran un perfil de Instagram institucional expresamente para la actividad. Como se puede comprobar en la fotografía del perfil (ver Figura 1), se emplearon imágenes extraídas de la página de uso libre "https://pixabay.com/":

Figura 1 - Perfil de Instagram competencia_comunicativa_i... $\vee \cdot=$

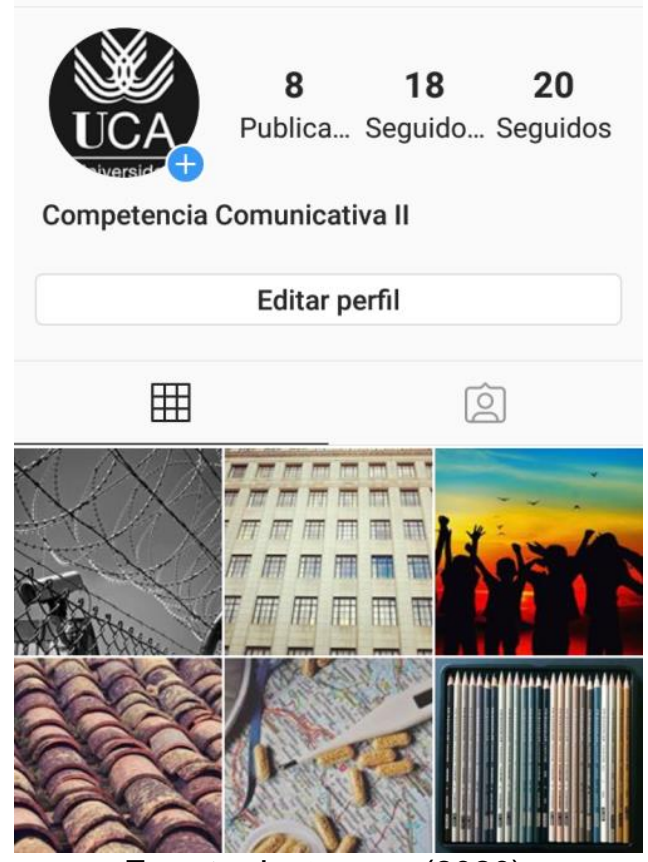

Fuente: Instagram (2020).

Con respecto al último instrumento, se hizo uso de un foro virtual en la plataforma de la UCA, Campus Virtual. A partir de este foro virtual, se estableció el grupo focal de esta investigación.

La obtención de datos parte de la presentación de las ocho imágenes subidas a Instagram durante ocho semanas. Estas se clasificaron inicialmente como positivas, negativas o neutrales, según los sentimientos que pudieran despertar entre los

4 "[...] alrededor del 40 por ciento de las publicaciones contienen al menos un emoji" (DANESI, 2016, p. 45 , se tradució).

Educ. Form., Fortaleza, v. 6, n. 1, e3528, jan./abr. 2021

DOI: https://doi.org/10.25053/redufor.v6i1.3528

https://revistas.uece.br/index.php/redufor/index 
informantes. Las temáticas escogidas pretendían ilustrar situaciones actuales conocidas por todos los estudiantes; por ejemplo: la pandemia de la Covid-19. Debían realizar sus comentarios restringiéndolos a 150 palabras, además de alternar obligatoriamente el uso las lenguas (español e inglés). La Tabla 1 ilustra la temporalización de la actividad:

Tabla 1 - Temporalización de la actividad

\begin{tabular}{|l|c|c|c|c|c|c|c|c|}
\hline Semanas & 1 & 2 & 3 & 4 & 5 & 6 & 7 & 8 \\
\hline Neutral & $\checkmark$ & & $\checkmark$ & & $\checkmark$ & & $\checkmark$ & \\
\hline Positivo & & $\checkmark$ & & & & $\checkmark$ & & \\
\hline Negativo & & & & $\checkmark$ & & & & $\checkmark$ \\
\hline
\end{tabular}

Fuente: Elaboración propia (2020).

Una vez comentadas las fotografías, se procedió a contar el número de emoji utilizados por cada estudiante en L1 y LE. Posteriormente, se clasificaron según las categorías establecidas por la Emojipedia ${ }^{5}$. Por último, se procedió a analizar la "gramática del emoji" según Danesi (2016): distribution, uses y utterances. Estos conceptos se ilustran en la sección de resultados. Finalmente, se procedió a corroborar los datos obtenidos con las propias opiniones de los informantes mediante un foro virtual.

\section{Resultados y discusión}

Los participantes que comentaron en L1 las cuatro imágenes son 18. Salvo dos estudiantes (12 y 18), el resto participó en el conjunto total de la actividad. El número total de emoji utilizados en L1 es 327 , siendo el promedio por comentario de 4,59, con rangos mínimo y máximo entre 0 y 23 . Se destaca el uso exponencial del número emoji por imagen, partiendo de 21 hasta llegar a 144. Las imágenes empleadas en L1 son de tipo 'neutral'. La Tabla 2 incluye la información sobre el uso de emoji en L1:

Tabla 2 - Emoji en L1

(continúa)

\begin{tabular}{|c|c|c|c|c|c|c|}
\hline Alumno & Imagen & $1(+/-)$ & $3(+/-)$ & $5(+/-)$ & $7(+/-)$ & Promedio \\
\hline 1 & 4 & 0 & 0 & 0 & 0 & 0,00 \\
\hline 2 & 4 & 0 & 1 & 8 & 10 & 4,75 \\
\hline 3 & 4 & 1 & 4 & 7 & 9 & 5,25 \\
\hline 4 & 4 & 0 & 0 & 12 & 23 & 8,75 \\
\hline 5 & 4 & 0 & 6 & 7 & 9 & 5,50 \\
\hline 6 & 4 & 0 & 1 & 8 & 14 & 5,75 \\
\hline 7 & 4 & 0 & 7 & 17 & 22 & 11,50 \\
\hline
\end{tabular}

5 Disponible en: https://emojipedia.org/. Accedido el: 10 oct. 2020.

Educ. Form., Fortaleza, v. 6, n. 1, e3528, jan./abr. 2021

DOI: https://doi.org/10.25053/redufor.v6i1.3528

https://revistas.uece.br/index.php/redufor/index 
Tabla 2 - Emoji en L1

(conclusión)

\begin{tabular}{|c|c|c|c|c|c|c|}
\hline Alumno & Imagen & $1(+/-)$ & $3(+/-)$ & $5(+/-)$ & $7(+/-)$ & Promedio \\
\hline 8 & 4 & 0 & 8 & 1 & 3 & 3,00 \\
\hline 9 & 4 & 4 & 4 & 0 & 3 & 2,75 \\
\hline 10 & 4 & 0 & 2 & 1 & 2 & 1,25 \\
\hline 11 & 4 & 2 & 0 & 7 & 4 & 3,25 \\
\hline 12 & 1 & 0 & - & - & - & 0,00 \\
\hline 13 & 4 & 10 & 4 & 5 & 1 & 5,00 \\
\hline 14 & 4 & 0 & 4 & 9 & 8 & 5,25 \\
\hline 15 & 4 & 1 & 8 & 11 & 16 & 9,00 \\
\hline 16 & 4 & 1 & 3 & 5 & 13 & 5,50 \\
\hline 17 & 4 & 2 & 0 & 2 & 7 & 2,75 \\
\hline 18 & 3 & 0 & 2 & 8 &. & 3,33 \\
\hline & & 21 & 54 & 108 & 144 & 4,59 \\
\hline
\end{tabular}

Fuente: Elaboración propia (2020).

Estos 18 estudiantes participaron también en LE, aunque solo seis comentaron las cuatro imágenes. El número total de emoji utilizados en las cuatro imágenes es 293. A diferencia de la actividad en $\mathrm{L} 1$, este promedio es 6,20 , con un incremento significativo entre la primera y la segunda imagen (+67), estabilizándose a partir de entonces. Las imágenes utilizadas en LE son de tipo "positivo" y "negativo". La Tabla 3 incorpora los datos:

Tabla 3 - Emoji en LE

\begin{tabular}{|c|c|c|c|c|c|c|}
\hline Alumno & Imagen & $2(+)$ & $4(-)$ & $6(+)$ & $8(-)$ & Promedio \\
\hline 1 & 2 & 0 & 0 & - & - & 0,00 \\
\hline 2 & 1 & 7 & - & - & - & 7,00 \\
\hline 3 & 4 & 1 & 11 & 11 & 10 & 8,25 \\
\hline 4 & 1 & - & 17 & - & - & 17,00 \\
\hline 5 & 3 & - & 9 & 6 & 13 & 9,33 \\
\hline 6 & 3 & 0 & 4 & - & 11 & 5,00 \\
\hline 7 & 1 & - & - & - & 12 & 12,00 \\
\hline 8 & 3 & - & 3 & 0 & 11 & 4,67 \\
\hline 9 & 2 & 2 & 14 & - & - & 8,00 \\
\hline 10 & 4 & 0 & 3 & 3 & 1 & 1,75 \\
\hline 11 & 1 & 0 & - & - & - & 0,00 \\
\hline 12 & 4 & 1 & 0 & 8 & 3 & 3,00 \\
\hline 13 & 4 & 0 & 5 & 22 & 0 & 6,75 \\
\hline 14 & 3 & - & 7 & 6 & 2 & 5,00 \\
\hline 15 & 4 & 8 & 9 & 13 & 8 & 9,50 \\
\hline 16 & 4 & 5 & 3 & 13 & 14 & 8,75 \\
\hline 17 & 3 & 3 & 0 & - & 0 & 1,00 \\
\hline 18 & 3 & 0 & 9 & 5 & - & 4,67 \\
\hline & & 27 & 94 & 87 & 85 & 6,20 \\
\hline
\end{tabular}

Fuente: Elaboración propia (2020).

Las categorías de la Emojipedia se asemejan entre L1 y LE. En primera posición, destaca la categoría de Smileys \& People: $44,65 \%$ y 45,73 \%, respectivamente. El resto

Educ. Form., Fortaleza, v. 6, n. 1, e3528, jan./abr. 2021

DOI: https://doi.org/10.25053/redufor.v6i1.3528

https://revistas.uece.br/index.php/redufor/index 
de las categorías de distribuyen de manera similar. En la Tabla 4 se incorporan los porcentajes, además de las categorías:

Tabla 4 - Emoji clasificados por categorías según la Emojipedia

\begin{tabular}{|l|c|c|c|c|}
\hline & \multicolumn{2}{|c|}{ L1 } & \multicolumn{2}{c|}{ LE } \\
\hline Smileys \& People & 146 & $44,65 \%$ & 134 & $45,73 \%$ \\
\hline Animals \& Nature & 49 & $14,98 \%$ & 44 & $15,02 \%$ \\
\hline Travel \& Places & 45 & $13,76 \%$ & 41 & $13,99 \%$ \\
\hline Objects & 41 & $12,54 \%$ & 32 & $10,92 \%$ \\
\hline Symbols & 36 & $11,01 \%$ & 31 & $10,58 \%$ \\
\hline Activity & 5 & $1,53 \%$ & 7 & $2,39 \%$ \\
\hline Food \& drink & 4 & $1,22 \%$ & 3 & $1,02 \%$ \\
\hline Flags & 1 & $0,31 \%$ & 1 & $0,34 \%$ \\
\hline & 327 & & 293 & \\
\hline
\end{tabular}

Fuente: Elaboración propia (2020).

Con respecto a "la gramática de los emoji" (DANESI, 2016), cabe destacar la similitud entre lenguas en materia de distribution. Tanto en L1 como LE, los participantes optan por el uso de emoji para representar un significado emocional en el mismo lugar del texto donde tiene cabida o semantic, con un $64,26 \%$ y un 77,09 \%; por ejemplo: "Una familia muy unida en LE. Segundo, emplean los emoji con el objeto de potenciar los significados que han sido indicados verbalmente o reinforcing, con un $30,04 \%$ y un $24,67 \%$; por ejemplo: ":Añoro esos momentos con todos mis primos", en L1; ye have been locked up Q?", en LE. La última posición la ocupan los emojis que se insertan en las oraciones donde se localizan signos de puntuación o fórmulas de saludo o syntactic, con un 5,70 \% en L1 (en LE no se registró ningún caso); por ejemplo: "(raza, etnias, culturas, capacidades, características....)":

Tabla 5 - Distribution

\begin{tabular}{|l|c|c|c|c|}
\hline & \multicolumn{2}{|c|}{ L1 } & \multicolumn{2}{c|}{ LE } \\
\hline Semantic & 169 & $64,26 \%$ & 175 & $77,09 \%$ \\
\hline Reinforcing & 79 & $30,04 \%$ & 56 & $24,67 \%$ \\
\hline Syntactic & 15 & $5,70 \%$ & 0 & $0,00 \%$ \\
\hline & 263 & & 231 & \\
\hline
\end{tabular}

Fuente: Elaboración propia (2020).

Los uses de los emoji se realizan casi en su totalidad de manera adjunctively al texto en L1 y LE, con un 83,27 \% y un 98,70 \%, respectivamente; por ejemplo: "Quédate

6 "La aterradora COVID-19 viene a nuestras mentes $:-$ " (se tradució).

7 "Nosotros hemos estado encerrados $\mathscr{Q}$ " (se tradució).

Educ. Form., Fortaleza, v. 6, n. 1, e3528, jan./abr. 2021

DOI: https://doi.org/10.25053/redufor.v6i1.3528

https://revistas.uece.br/index.php/redufor/index 


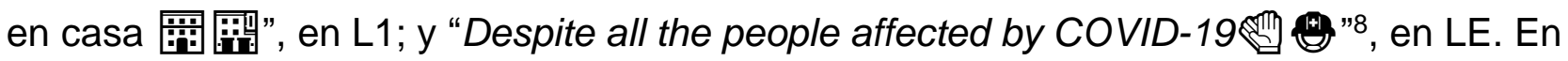
cambio, los emoji apenas tienen presencia como sustitutive de texto en L1 (16,73\%) o

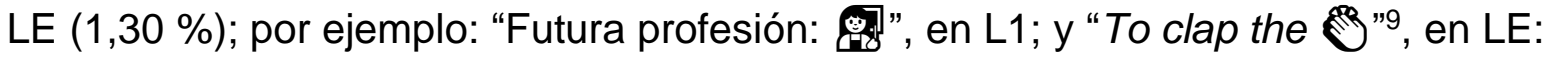

Tabla 6 - Uses

\begin{tabular}{|l|c|c|c|c|}
\hline & \multicolumn{2}{|c|}{ L1 } & \multicolumn{2}{c|}{ LE } \\
\hline Adjunctively & 219 & $83,27 \%$ & 228 & $98,70 \%$ \\
\hline Sustitutive & 44 & $16,73 \%$ & 3 & $1,30 \%$ \\
\hline & 263 & & 231 & \\
\hline
\end{tabular}

Fuente: Elaboración propia (2020).

En relación con las funciones fáticas del emoji, la distribución de los utterances, enunciados o producciones lingüísticas se mantiene similar para ambas lenguas. Solo un $19,47 \%$ en L1 y un $21,16 \%$ en LE de los emoji analizados entran dentro de esta categoría. Primero, los emoji ejercen como elementos que representan una fórmula de despedida utterance ending para un 70,31\% y un 75,81 \% en L1 y LE, respectivamente; por ejemplo: “Aprenderemos sin duda alguna. 응, en L1; y "We'll see each other soon! 抣 "10, en LE. Segundo, los emoji se utilizan como elemento que, en forma de saludo, pretende llamar la atención del lector o utterance opener, aunque estos casos se limitan a un $21,88 \%$ en L1 y un $24,19 \%$ en LE; por ejemplo: “ $\bigcirc$ esta fotografía me recuerda a la emergencia sanitaria que estamos sufriendo en la actualidad", en L1; y “C This publication reminds me of..."11, en LE. Tercero, los emoji se insertan con la finalidad de o evitar silencios o silence avoiding, con un 7,81 \% en L1, mientras que no se han observado casos LE; por ejemplo: "Hay anécdotas por descubrir en ese lugar 0 㸺

Tabla 7 - Utterances

\begin{tabular}{|l|c|c|c|c|}
\hline & \multicolumn{2}{|c|}{ L1 } & \multicolumn{2}{c|}{ LE } \\
\hline Ending & 45 & $70,31 \%$ & 47 & $75,81 \%$ \\
\hline Openinig & 14 & $21,88 \%$ & 15 & $24,19 \%$ \\
\hline Silence avoiding & 5 & $7,81 \%$ & 0 & $0,00 \%$ \\
\hline & 64 & & 62 & \\
\hline
\end{tabular}

Fuente: Elaboración propia (2020).

\footnotetext{
8 “A pesar de todas las personas afectadas por COVID-19 (se tradució).

9 "Para aplaudir (se tradució).

10 "Nos veremos pronto "se tradució).

11 "(O) Esta publicación me recuerda a..." (se tradució).
}

Educ. Form., Fortaleza, v. 6, n. 1, e3528, jan./abr. 2021

DOI: https://doi.org/10.25053/redufor.v6i1.3528

https://revistas.uece.br/index.php/redufor/index 
Como se ha indicado, se gestionó un foro virtual desde donde se constituye el grupo focal de esta investigación. En dicho foro intervinieron 16 de los 18 estudiantes. Tanto las preguntas como los tópicos que se han extraído de la categorización de las respuestas de los estudiantes se detallan a continuación: 1. Cuando utilizas emoji en redes sociales, como Instagram, por ejemplo, o aplicaciones de chat o mensajería, ¿cómo defines tu estilo (agrupas los emoji, los repites, etc.)?; 2. ¿Has notado alguna diferencia en el uso de emoji entre comentar las fotos de Instagram en L1 o en LE?: 3. Según el análisis de vuestros comentarios en Instagram, los emoji se emplean en L1 con más asiduidad para enfatizar los verbos, mientras que en inglés LE, con los nombres. ¿Hasta qué punto crees que influye la L1 o la LE en el uso de emoji?; 4. Desde un punto de la sintaxis (la organización de las palabras para formar oraciones correctas), los emoji no suelen sustituir a los elementos en una oración (por ejemplo: palabras 0 signos de puntuación) tanto en L2 como, sobre todo, en LE, según el análisis de vuestros comentarios en Instagram. ¿Por qué crees que esto ocurre?; 5. Aunque el tipo de textos analizados en la actividad de Instagram no implica el uso extendido de emoji para "evitar silencios" o terminar una oración o conversación, sí se han recopilado algunos ejemplos en L1, pero no en LE. ¿En qué crees que influye el uso de una lengua $u$ otra para que esto suceda?; 6. En relación con el análisis de vuestros comentarios sobre las fotos de Instagram, los emoji en L1 sirven como sustitutos de palabras o expresiones con más frecuencia que en LE. ¿Cómo crees que el grado de conocimiento de la LE afecta al uso de emoji?; 7. Al respecto de la pregunta anterior, ¿crees que la cultura dominante en una persona determina el uso de unos emoji u otros?; 8. Por último, por un lado, ¿crees que los emoji se pueden utilizar en la enseñanza de la L1? ¿De qué manera(s)?; y 9. Por otro lado, ¿crees que los emoji se pueden utilizar en la enseñanza de una lengua LE? ¿De qué manera(s)?

Emoji imprescindibles para una vida virtual. Con respecto a la primera pregunta planteada, se evidencia que ocho estudiantes $(50,00 \%)$ emplean los mismos emoji, haciendo uso de la herramienta "recientes", a la vez que dos estudiantes $(12,50 \%)$ señalan que "No sabría llevar una vida virtual sin emoji" (estudiante 11, comunicación personal, 12 de mayo de 2020) y que "No sé si podríamos vivir sin emoji" (estudiante 14, comunicación personal, 12 de mayo de 2020). De hecho, otro informante $(6,25 \%)$ cataloga directamente su uso como "imprescindible" (estudiante 7, comunicación 
personal, 12 de mayo de 2020). Solo dos (12,50 \%) confiesan no hacer uso frecuente de los emoji, de los que uno de ellos $(6,25 \%)$ argumenta usarlos solo "Para quitarle peso a lo que se está diciendo" (estudiante 10, comunicación personal, 12 de mayo de 2020).

De los demás, su uso se realiza normalmente en las redes sociales (RRSS) $(\mathrm{N}=6)$, repitiéndose WhatsApp, Twitter e Instagram como las preferidas. Solamente dos informantes $(12,50 \%)$ señalan tener preferencias de emoji para unas RRSS u otras: "Uso de emoji para matizar los mensajes, sin repetir emoji, buscando un mensaje armónico" (estudiante 15, comunicación personal, 12 de mayo de 2020)

En relación con el porqué del uso de emoji, siete declaran (43,75\%) usarlos para reforzar o representar sentimientos, incluso uno de ellos declara que "La cantidad de emoji depende del grado de intensidad de la emoción" (estudiante 15, comunicación personal, 12 de mayo de 2020). Además, seis de ellos (37,50 \%) hacen uso de estos para sustituirlos por palabras - sean obvias o no - y para facilitar la comprensión y clarificar el sentido. Es interesante también que dos de ellos (12,50 \%) indiquen que su uso está descendiendo y está siendo sustituido por el uso de stickers y GIF, ya que piensan que aportan mayor claridad en los mensajes.

Pese al gran uso de emoji que aparentemente realiza el alumnado, es determinante conocer que se repite en cuatro de ellos $(25,00 \%)$ la idea de que su uso no está ampliamente aceptado en situaciones formales o con personas que no conocen y, sobre todo, en determinados ambientes más formales, como el laboral, por ejemplo.

Emoji para expresar sentimientos. Para la pregunta dos, 11 informantes $(68,75 \%)$ contestaron "no", a diferencia de cinco, que dijeron "sí". Entre las razones de los que respondieron afirmativamente, se observa que lo achacan a que están acostumbrados al uso del inglés en situaciones formales, en las que no se hace uso de los emoji. Uno de ellos $(6,25 \%)$ también expresa que se asocia el uso de emoji a los sentimientos o los pensamientos, es decir, al carácter más emocional de la lengua. Por lo tanto, es más frecuente en L1. También se manifiesta un uso simultáneo del emoji en L1, mientras que, en LE, primero escribían el comentario y luego añadían los emoji: "En inglés era más difícil expresar lo que quería decir, por lo que era más difícil encontrar un icono" (estudiante 10, comunicación personal, 12 de mayo de 2020).

En relación con los informantes que contestaron que no habían notado la diferencia, se encuentran respuestas como, por ejemplo: "Los emoji son universales y se 
crearon para darle solución a los problemas de la lengua escrita" (estudiante 2, comunicación personal, 12 de mayo de 2020) o que "Si entendemos lo que estamos escribiendo, deberíamos conocer qué emoji es necesario en cada situación" (estudiante 7, comunicación personal, 12 de mayo de 2020). De estos, dos de ellos (12,50 \%) manifiestan un uso un tanto forzado de los emoji, mientras que otro declara que lo realmente difícil era la temática.

Complejidad en L1 y formalidad LE para el uso de emoji. De la tercera pregunta, cuatro informantes $(25,00 \%)$ no creen que haya diferencia. Aun así, de los demás informantes, tres señalan $(18,75 \%)$ el uso de los sustantivos en LE para facilitar la comprensión. Además, cuatro declaran (25,00 \%) que, por ser el español la L1, estrañan que sean capaces de representar acciones más complejas y mucho más simples en LE (uso del sustantivo), insistiendo en que no influyen el idioma en sí, sino el dominio que se tenga de él. Además, son interesantes relatos como que la formalidad de la LE no lleva a usar emoji de manera natural (en lo que se hizo hincapié en las respuestas anteriores: que los verbos indican una acción y en L1 siempre se representa realizar actividades con emoji; que el estudio de la sintaxis se ha ceñido a la L1 y no a la LE; o la cuestión de que se han encontrado con un estudio muy intensivo del léxico en LE.

Emoji como complemento y formalidad en el formato escrito. De la cuarta pregunta, 13 de los informantes $(81,25 \%)$ señalan que la causa principal es el uso del emoji como complemento, y no como sustituto. De estas respuestas, algunos de ellos matizan esta idea principal con otras como la ambigüedad de alguno de los emoji o la dificultad del proceso de lectura si se produce una sustitución en vez de una complementación. Además, cuatro $(25,00 \%)$ de los estudiantes hacen hincapié en la formalidad del escrito, lo que dificulta la sustitución de elementos de la oración.

Carácter académico y formal de la $L E$ y la naturalidad en el uso de la L1. Relacionado con la quinta cuestión, todos los informantes coinciden, básicamente, en dos ideas principales: el carácter académico y formal de la LE y la naturalidad en el uso de la L1. Además, se resaltan otras ideas, como que los emoji se ligan a prácticas culturales en todos los idiomas y al dominio o no de una lengua u otra.

El grado de conocimiento de la LE afecta al uso de emoji y obviedad de la cultura con respecto a su uso. Conforme a la sexta pregunta, los 16 informantes $(100,00 \%)$ coinciden en que el grado de conocimiento afecta al uso del emoji. Cinco de ellos 
$(31,25 \%)$ resaltan que es debido a la acomodación del discurso para su entendimiento, aunque se señalan otras ideas interesantes como el uso del emoji para una mejor comprensión del texto, el desconocimiento de aspectos culturales vinculados a una LE o el desconocimiento del uso de la LE en contextos formales e informales.

Ligado a esta idea, en la pregunta siete, los 16 informantes $(100,00 \%)$ determinan que sí afecta, aduciendo razones como la distinción entre las generaciones de usuarios o que "El uso o no de emoji dependerá del respeto que le tengas al intermediario" (estudiante 14, comunicación personal, 12 de mayo de 2020). No obstante, es curioso que en esta pregunta los informantes no realizan reflexiones muy profundas sobre el carácter del emoji y su uso en relación con la cultura del usuario.

Estrategias didácticas e inclusión de los emoji en L1 y en LE. Finalmente, en la pregunta ocho, los 16 informantes (100,00\%) vuelven a coincidir en que los emoji pueden utilizarse como recurso didáctico. De estos, ocho (50,00 \%) afirman que se podría trabajar la educación emocional o el desarrollo de la personalidad; dos de ellos $(12,50 \%)$, para el fomento de la competencia comunicativa (oral y escrita), haciendo mención a aspectos como el uso del vocabulario; cuatro $(25,00 \%)$ hacen hincapié en el aprendizaje y puesta en práctica de la L1; y uno $(6,25 \%)$ en el conocimiento y aplicación de los emoji. Además de esas ideas, el alumnado ofrece interesantes estrategias y la inclusión de los emoji en la metodología diaria, como el apoyo visual para la enseñanza; su beneficio en el desarrollo de la interculturalidad y competencia sociocultural; sustitutos de otras actividades; o en cuentacuentos y representaciones de historias.

En relación con su uso en lengua extranjera (pregunta 9), los 16 informantes $(100,00 \%)$ también afirman que sí se pueden aplicar a la enseñanza de la LE. En este sentido, 14 de ellos (87,50 \%) coinciden en el aprendizaje del vocabulario; uno en el desarrollo de la competencia intercultural; y otro en la facilitación del andamiaje en el aprendizaje. Asimismo, al igual que en la L1, el alumnado ofrece distintos motivos, estrategias y métodos de inclusión de los emoji, como, por ejemplo, como técnica de motivación; de nuevo para trabajar la educación emocional o el desarrollo de la personalidad; sus beneficios para el desarrollo de la competencia escrita o como apoyo visual; o para rebajar el filtro de tensión debido a la falta de competencia idiomática. 


\section{Consideraciones finales}

Con el presente estudio se han podido atisbar posibles aplicaciones didácticas de los emoji para el desarrollo de la competencia en lengua escrita en español (lengua materna) e inglés (lengua extranjera). Si bien Instagram es la plataforma escogida para registrar los comentarios de las diferentes imágenes, se reconocen las posibilidades de uso de los emoji en textos académicos, lo que sirve para asociar un "high (formal) value" a "online writing" (DANESI, 2016, p. 97). Asimismo, aunque los emoji no se emplean habitualmente en contextos de escritura formal o no están inicialmente creados para expresar algo serio o, incluso, grave (DANESI, 2016), este trabajo deja constancia de las peculiaridades de los emoji como elementos visuales y "representante[s] del ámbito conceptual" (HIGHFIELD; LEAVER, 2016): los emoji permiten a sus usuarios condensar grandes cantidades de información en mínimas unidades visuales, representadas en smileys como (-), por ejemplo.

Sobre las posibilidades didácticas de los emoji para el desarrollo de la competencia escrita en textos académicos en L1 y LE - y si los creadores de los emoji tenían como objetivo "[...] to make written communication between anyone, regarless of language background, more and more possible"12 (DANESI, 2016, p. 95) -, podrían utilizarse en el ámbito de la enseñanza de lenguas. Incluso, los emoji pueden emplearse para el desarrollo de una "meta-literacy awareness" (DANESI, 2016, p. 97), es decir, la construcción progresiva de un propio conocimiento sobre las destrezas lingüísticas a partir de la correcta aplicación de los emoji como elementos conceptuales. Por otra parte, con respecto a las posibilidades didácticas, se corrobora la postura de Prensky (2010) al principio de este artículo con estas palabras de Londoño (2018): "[...] en lugar de restarle valor a las metas de aprendizaje, las vidas ricas en redes sociales de nuestros alumnos pueden contribuir a un aprendizaje más profundo".

Asimismo, la naturaleza conceptual del emoji facilita el tratamiento de tópicos en lengua escrita que pudieran resultar inicialmente complicados de gestionar (DANESI, 2016) por los aprendientes, sobre todo en LE, por su carácter formal, como se hizo

12 "[...] hacer que la comunicación escrita entre cualquier persona, independientemente de su origen lingüístico, sea cada vez más posible" (DANESI, 2016, p. 95, se tradució).

Educ. Form., Fortaleza, v. 6, n. 1, e3528, jan./abr. 2021

DOI: https://doi.org/10.25053/redufor.v6i1.3528

https://revistas.uece.br/index.php/redufor/index 
hincapié en el foro virtual. Con vistas a la labor docente en etapas como Educación Primaria, por ejemplo, cabe recordar que la aplicación de emoji no supone una disrupción con la sintaxis de la lengua meta, tanto L1 como LE (DANESI, 2016), sino que el texto se refuerza mediante signos visuales que se intercalan sistemáticamente (DANESI, 2016), sustituyendo o potenciando a clases de palabras, como verbos, adjetivos, adverbios $\mathrm{o}$, incluso, a expresiones completas.

Partiendo de que los emoji representan unidades visuales que pueden insertarse en textos de manera individual o grupal y que, al mismo tiempo, contienen información contextual, pueden definirse como "metaphorical pictures" (DANESI, 2016, p. 66). Por consiguiente, pueden emplearse no solo como elementos que sustituyen o acompañan al texto, con independencia de la lengua meta, sino también como impulsores de actividades destinadas a potenciar la creatividad del estudiante a partir de su propia interpretación, que dependerá, a su vez, de connotaciones culturales. En resumen, la Tabla 8 incorpora el cotejo entre los objetivos, generales y específicos, y las hipótesis de investigación:

Tabla 8 - Objetivos e hipótesis de investigación

(continúa)

O.1. La gramática de los emoji se ajusta a las reglas de la sintaxis y semántica (DANESI, 2016) en L1 y en LE. Pueden utilizarse como recursos para el desarrollo de la competencia escrita en textos académicos, sobre todo cuando ejercen como potenciadores de significado debido a su propia naturaleza conceptual, pero no (o no tanto) como sustitutos de texto.

O.2. El análisis del uso de emoji denota rasgos conductuales similares para distribution, uses y utterances, con mínimas diferencias entre lenguas. Esto supone una aplicación casi sistemática de los emoji con independencia de la lengua meta, lo que establece la naturaleza conceptual de los emoji, pudiendo acompañar a textos en cualquier lengua natural.

02.1. En términos de sintaxis, los emoji apenas sustituyen a texto, sobre todo en LE. Esto supone que los usuarios solo los utilizan como tal (sustitutos de texto) cuando prevén que el receptor en capaz de entender plenamente el significado transmitido. Así que este recurso apenas tiene cabida en LE.
H.1. La transición entre textos no académicos a académicos está supeditada a las condiciones de escritura en el contexto de aprendizaje. La inclusión de emoji no determina el registro académico o no de un texto, sino que depende de la lengua de uso, así como del formato y las normas de redacción, como se ha podido observar en los comentarios de Instagram.

H.2. El comportamiento de los emoji evidencia similitudes entre lenguas. Según Danesi (2016, p. 78), esto se debe a que los "[...] the intertwining of the semantic, syntactic and pragmatic dimensions of the emoji code allows users to engage in the cognitive flow of a text and thus either to produce of comprehend its meaning" 13 .

H.2.1. Los emoji (unidades visuales) potencian el significado conceptual del texto al que acompañan. Con todo, según Danesi (2016, p. 78), su gramática implica más que la de una lengua a la que se le unen símbolos visuales, sino que "[...] it has its own 'syntactic' or system for organizing the emoji to create coherent and meaningful sequences of combinations" 14 .

13 “[...] el entrelazamiento de las dimensiones semántica, sintáctica y pragmática del código emoji permite a los usuarios participar en el flujo cognitivo de un texto y así producir o comprender su significado" (DANESI, 2016, p. 78, se tradució).

14 "[...] tiene su propio 'sintáctico' o sistema para organizar el emoji para crear secuencias de combinaciones coherentes y significativas" (DANESI, 2016, p. 78, se tradució).

Educ. Form., Fortaleza, v. 6, n. 1, e3528, jan./abr. 2021

DOI: https://doi.org/10.25053/redufor.v6i1.3528

https://revistas.uece.br/index.php/redufor/index 
Tabla 8 - Objetivos e hipótesis de investigación

O.2.2. La función de los emoji es potenciar el significado para otorgar connotaciones emocionales al texto, es decir, los emoji "[...] reinforce, expand, and annotate the meaning of a written communication" (DANESI, 2016: 15). En el escenario de confinamiento por la COVID-19 en donde se realizó la actividad, los emoji denotaban incluso más su carácter conceptual, sirviendo como elementos que reforzaron las ideas escritas, en muchas ocasiones de esperanza o tristeza. (conclusión)

H.2.2. El uso de emoji es conceptual: "[...] their function is thus neither purely substitutive nor decorative [...]. They are meaning-enhancing devices that are amalgamated with alphabetic ones, turning modern-day informal writing into a unique kind of bimodal system" (DANESI, 2016, p. 15). En ocasiones, es más sencillo para los usuarios utilizar emoji para representar emociones que el texto escrito per se.

Fuente: Elaboración propia (2020).

Tras estas consideraciones, valoramos las limitaciones de este estudio. Tal y como se señalaba al principio, los primeros emoji se desarrollaron a finales de los años noventa. En estos veinte años, pocos han sido los estudios donde se analicen los emoji desde una vertiente lingüística sólida, por lo que una de las máximas limitaciones de este estudio es la exigua bibliografía incluida dentro de revistas científicas y de impacto sobre el tema. Es por ello por lo que se ha hecho hincapié en investigaciones como la de Danesi (2016) - piedra angular para nuestro estudio - o Evans (2017).

Por último, después de este primer análisis donde se atisba el empleo de emoji como recurso para el desarrollo de la competencia escrita en contextos académicos formales, se proponen futuras líneas de investigación y prospección en las que se analizarán los tipos de textos empleados por los estudiantes, categorizándolos en las cuatro grandes categorías de textos 0 , en su defecto, en secuencias textuales de los tipos: expositivos, narrativos, argumentativos y descriptivos. Además, se pretende relacionar el empleo de emoji con las características lingüísticas y textuales de estos tipos de textos o secuencias textuales.

\section{Referencias}

ÁLVAREZ, E.; HEREDIA, H.; ROMERO, M. F. La Generación Z y las redes sociales. Una visión desde los adolescentes en España. Revista Espacios, [S.I.], v. 40, n. 20, p. 9-21, 2019. Disponible en: http://www.revistaespacios.com/a19v40n20/a19v40n20p09.pdf. Accedido el: 11 jul. 2020.

BOA SORTE, P. Memes de internet: perspectivas para el salón de clase en el contexto de las culturas digitales. Educação \& Formação, Fortaleza, v. 4, n. 3, p. 51-66, 2019. 
Disponible en: https://revistas.uece.br/index.php/redufor/article/view/1385/1307. Accedido el: 11 jul. 2020.

CONSEJO DE EUROPA. Marco común europeo de referencia para las lenguas: aprendizaje, enseñanza y evaluación. Madrid: Secretaría Técnica del MEC, Anaya e Instituto Cervantes, 2002.

DANESI, M. The semiotics of emoji: the rise of visual language in the age of the internet. Nueva York: Bloomsbury Academic, 2016.

EVANS, V. The emoji code: how smiley faces, love hearts and thumbs up are changing the way we communicate. New York: Picador, 2017.

HERNÁNDEZ SAMPIERI, R.; FERNÁNDEZ COLLADO, C.; BAPTISTA LUCIO, P. Metodología de la investigación. 6. ed. México, DF: McGraw-Hill, 2016.

HIGHFIELD, T.; LEAVER, T. Instagrammatics and digital methods: studying visual social media, from selfies and GIFs to memes and emoji. Communication Research and Practice, London, v. 2, p. 47-62, 2016. Disponible en: https://espace.curtin.edu.au/bitstream/handle/20.500.11937/36939/240444.pdf?sequence $=2 \&$ isallowed $=y$. Accedido el: 11 jul. 2020 .

JIBRIL, T. A.; ABDULLAH, M. H. Relevance of emoticons in computer-mediated communication contexts: an overview. Asian Social Science, Ontario, v. 4, n. 9, p. 201207, 2013. Disponible en:

http://www.ccsenet.org/journal/index.php/ass/article/view/26102. Accedido el: 11 jul. 2020.

LONDOÑO, C. ¿Cómo transformar los emojis en un recurso pedagógico?. Elige educar (blog), 2018. Disponible en: https://eligeeducar.cl/transformar-los-emojis-recursopedagogico-esta-profesora-nos-cuenta. Accedido el: 11 jul. 2020.

LÓPEZ PENA, Z. El análisis multimodal del anuncio publicitario audiovisual para el aula de Lengua Castellana y Literatura en Educación Secundaria y Bachillerato. Educação \& Formação, Fortaleza, v. 5, n. 15, p. 1-16, 2020. Disponible en:

https://revistas.uece.br/index.php/redufor/article/view/2839/2798. Accedido el: 11 jul. 2020.

PRENSKY, M. Enseñar a nativos digitales. Madrid: SM, 2011.

PRENSKY, M. Nativos e inmigrantes digitales. Cuadernos SEK 2.0, p. 3-20, 2010.

Disponible en: https://www.marcprensky.com/writing/prenskynativos\%20e\%20inmigrantes\%20digitales\%20(sek).pdf. Accedido el: 11 jul. 2020.

ZHOU, R.; HENTSCHEL, J.; KUMAR, N. Goodbye text, hello emoji: mobile communication on WeChat in China. CHI Conference, p. 6-17, 2017. Disponible en: http://www.tandem.gatech.edu/wp-content/uploads/2017/01/chi17-zhougoodbyetexthelloemoji.pdf. Accedido el: 11 jul. 2020. 
Milagrosa Parrado-Collantes, Universidad de Cádiz, Departamento de Didáctica de la Lengua y la Literatura

i(i)https://orcid.org/0000-0003-3250-496X

Profesora e investigadora del Departamento de Didáctica de la Lengua y la Literatura de la Universidad de Cádiz. Doctora por la Universidad de Cádiz en 2017 con la tesis doctoral titulada La recepción de Carlos Edmundo de Ory en las aulas de Educación Secundaria Obligatoria de Cádiz: el caso de los Aerolitos. Centra sus investigaciones en el ámbito de la educación literaria; la Literatura Infantil y Juvenil; la microficción; el fomento de la lectura; el canon literario y el canon educativo; el autor gaditano Carlos Edmundo de Ory.

Contribución de autoría: Introducción, análisis de grupo focal y conclusiones.

E-mail: milagrosa.parrado@uca.es

José Luis Estrada-Chichón, Universidad de Cádiz, Departamento de Didáctica de la Lengua y la Literatura

ii (iDhttps://orcid.org/0000-0003-3274-6133

Profesor del Departamento de Didáctica de la Lengua y la Literatura (Universidad de Cádiz, España). Doctor en la enseñanza de lenguas. Sus intereses de investigación se centran en ISLA (Instructed Second Language Acquisition); educación bi/plurilingüe; CLIL (Content, Language, Integrated, Learning); EMI (English as a Medium of Instruction); $y$ formación docente.

Contribución de autoría: Resultados, metodología y conclusiones.

E-mail: joseluis.estrada@uca.es

Editora responsable: Lia Machado Fiuza Fialho Pareceristas ad hoc: Enrique Sologuren Insúa y Álvaro Pérez García

\section{Cómo citar este artículo (ABNT):}

PARRADO-COLLANTES, Milagrosa; ESTRADA-CHICHÓN, José Luis. Emoji y expresión escrita: posibilidades de aplicación y desarrollo en lenguas materna y extranjera. Educ. Form., Fortaleza, v. 6, n. 1, e3528, 2020. Disponible en: https://revistas.uece.br/index.php/redufor/article/view/3528

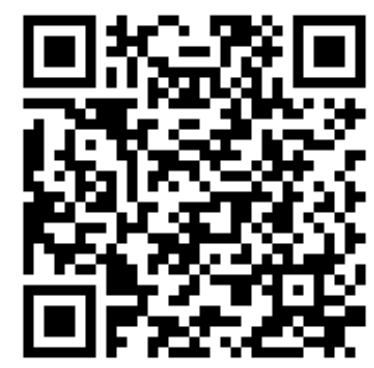

Recibido el 9 de julio de 2020.

Aceptado el 6 de agosto de 2020.

Publicado el 16 de noviembre de 2020.

Educ. Form., Fortaleza, v. 6, n. 1, e3528, jan./abr. 2021

DOI: https://doi.org/10.25053/redufor.v6i1.3528

https://revistas.uece.br/index.php/redufor/index 